\title{
Bibliografía de Neruda en Italia
}

\section{a) Traducciones}

1.-Si desti il taglialegna, traducción de Dario Puccini y Mario Socrate, Roma, Rinascita, 1951.

2.-Poesie di Neruda, traducidas por Salvatore Quasimodo, Torino, Einaudi, 1952.

3.-Canto generde (I-IV), por D. Puccini, Parma, Guanda, 1955.

4.-P. Neruda, Poesie, por G. Bellini, Milano, Nuova Accademia, 1960.

5.-Venti poesie d'amore e una canzone disperata, por G. Bellini, ibidem, 1962.

Pagine d'autunno, por G. Bellini, Firenze, ibidem, 1962.

6.-P. Neruda, Poesíie, por D. Puccini, Firenze, Sansoni, 1962.

7.-Stravagario, traducción de G. Bellini, Milano, Nuova Accademia, 1963.

8.-Poesia d'amore, traducción de G. Bellini, ibídem, 1963.

9. Sommario, Libro dove nasce la pioggia, traducción de G. Bellini, Alpignano, Tallone, 1963.

10.-I versi del Capitano, traducción de G. Bellini, Milano, Nouva Accademia, 1965.

11.-Memoriale di Islat Negra, traducción de G. Bellini, ibi, 1965 .

12.-Antología poética, por G. Bellini, Milano, Mursia, 1968.

13. - Todo el amor, traducción de G. Bellini, Milano, Sansoni-Accademia, 1968.

14.-Tre Residenze sulla terra, traducción de G. Bellini, ibidem, 1969.

15.-Crepuscolario, Venti poesie d'amore e una canzone disperata, Tentativo dell'uomo infinito, L'abitante e la sua speranza, Anelli, Il frombolieve endosiano, traducción de G. Bellini, Milano, ibid, 1969.

16.-Canto generole (2 vol.), por D. Puccini, Milano, Accademia-Sansoni, 1971.

17.-Fine del mondo, por G. Bellini, Milano, Accademia, 1972. 
b) Antologías (en que aparecen poemas de P. Neruda)

1.-Poesia ispano-americana del '900, por Francesco Tentori, Parma, Guanda, 1957.

2.- Antologia della poesia straniera, dirigida por Attilio Bertolucci, Milano, Garzanti, 1958.

3.-Romancero della Resistenza espagnola, por D. Puccini, Milano, Feltrinelli, 1961.

4.-Orfeo, il tesoro della lirica universale, por Emilio Mariano, Firenze, Sansoni, 1961.

5.-Italia dei poeti, por E. Mariano, Milano, Nuova Accademia, 1961.

6.-Poeti ispanoamericani contemporanei, por Marcello Ravoni y Antonio Porta, Milano, Feltrinelli, 1970.

7.-Poeti ispanoamericani del '900, por F. Tentori Montalto, Torino, ERI-Edizioni RAI Radiotelevione Italiana, 1972.

c) CRÍtica

1.-Puccini D., Lettura del "Canto general" di Pablo Neruda, Società, Torino, 1950, VI, 4.

2.-IDEM, La poesia di Nerida tra la metafora e l'epos, America Latinc, Milano, 1952, I, 1.

3.-IDEM, Introduzione alla traduzione del Canto general, Parma, Guanda, 1955.

4.- IDEM, L'ullimo Neruda. Los sentimientos primordiales. Il Contemporaneo, Roma, giugno 1956.

5.--IDEM, Introduzione a P. Neruda, Poesie, Firenze, 1962.

6.-IDEM, Due note su Pablo Neruda, Studi di letteratura Spagnola, Roma, 1965.

7.-IDEM, Introduzione a Canto general (2 vol.), Milano, AccademiaSansoni, 1971.

8.-Contessi P. L., Poesia e apologia politica ( $A$ proposito di Pablo Neruda), Il Mulino, Bologna, 1953, 16.

9.-Avila P. L., Viaje al corazón de Neruda, in P. Neruda. Antología poética, Torino, Gheroni, 1962.

10.-Bellini G., Introduzione alla poesia di Pablo Neruda, en $P$. Nerudd, Poesie, Milano, Nuova Accademia, 1960.

11.-IDEM, Introduzione a P. Neruda, Pagine d'autunno, ibi, 1962. 
12.- IDEM, Introduzione a P. Neruda, Venti poesie d'amore e una canzone disperata, ibi, 1962.

13.-IDEM, Nota finale a P. Neruda, Sommario, Libro dove nasce la pioggia, Alpignano, Tallone, 1963.

14.--IDEM, Introduzione a P. Neruda, Stravagario, Milano, Nuova Academia, 1963.

15.-IDEM, Introduzione a P. Neruda, Poesia d'amore, ibi, 1963.

16.-IDEM, Introduzione a P. Neruda, Memoriale di Isla Negra, ibi, 1965.

17.-IDEM, Intraduzione a P. Neruda, Canto general, ibi, 1965.

18.-Idem, La poesia di Pablo Neruda Da Estravagario a Memorial de Isla Negra, Padova, Liviana, 1966.

19.-IDem.-Introduzione a P. Neruda, Tres Residenze sulla terra, Milano, Accademia-Sansoni, 1969.

20.-IDEM, Introduzione a P. Neruda, Crepusculario..., etc.; Milano, Accademia-Sansoni, 1969.

21.-IoEm, Introduzione a P. Neruda, Fine del mondo, Milano, Accademia-Sansoni, 1972.

22.-Macri O., Pablo Neruda in italiano, La Nazione, Firenze, 10 giugno, 1962.

23.-Coco B., La sterile esperienza marxista di P. Neruda, Letture, Mi. lano, 1962, XVII, 2.

24.-Bodini V., Pablo Neruda e la "generación", Il Mondo, 1962, $\mathrm{XIV}, 27$.

25.-Terracini L., Il "Sumario" di Pablo Neruda e la poesia della me. moria, Roma, 1964.

26.-Melis A., Neruda, Il Castoro, Firenze, La Nouva Italia, 1970, 38.

GABRIELE MORELLI

Milano, mayo de 1972 